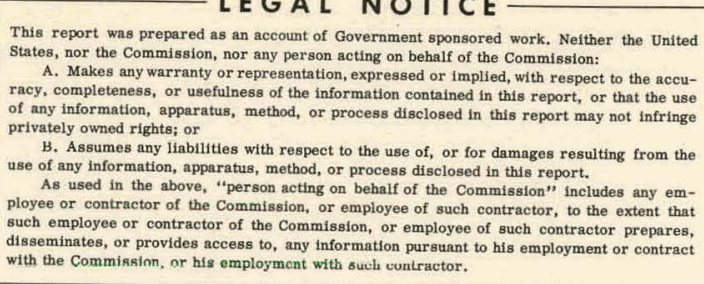

\title{
AN APPLICATION OF GAME THEORY TO SPECIAL WEAPONS EVALUATION
}

\author{
J. K. Hale and H. H. Wicke* \\ Sandia Corp., Albuquerque, N.M.
}

\section{INTRODUCTION}

Current (1956) published literature pertaining to special weapons selection and evaluation makes it appropriate to preface this paper with a few remarks on the use of a gametheoretic approach and on the motivation for the use of Lanchester theory. One currently much-employed approach to weapons evaluation is to choose models for weapon and target and to calculate damage. The results of a careful calculation, judiciously handled, can be of assistance in weapons evaluation. It is reasonable to assume, however, that in future wars both sides will have atomic weapons and both sides will be forced to develop protective measures to survive. A major means of protection which has been considered here to the exclusion of others is the manner in which opposing troops are disposed on the battle field.

That troop disposition is important can be seen from simple considerations. If enemy troops are in a long, thin line close to friendly troops, a large-yield weapon employed by friendlies will be ineffective, while several small-yield weapons can be quite effective. On the other hand, if troops are more widely dispersed, a large yield will be more effective than a small yield. (The military effect of the troop dispersion will be discussed in a later paragraph.)

These considerations lead to questions as to yields and troop formations. In this paper a simple battle situation in which these elements enter has been devised in order to get some rough indications of what answers to expect to these questions. The present model can be refined in many ways, but even this first approximation points out some trends and shows need for further thinking on the subject.

The most important point is, however, that one needs answers to these questions (as well as many others) to avoid disaster. As can be readily shown, the use of one kind of weapons system or of one kind of troop formation can lead to defeat. One needs only to reflect that, given a weapon system, one can usually develop tactics which will render that system ineffective (unless one is forced by other considerations, such as terrain, to maintain a certain formation). Thus it appears that at least two different weapons systems and two different troop formations should be employed. To find out exactly what strategies to use, the ideal procedure would seem to be to set up a continuous game in which each player's strategy

*Manuscript received February 19, 1957 


\section{DISCLAIMER}

This report was prepared as an account of work sponsored by an agency of the United States Government. Neither the United States Government nor any agency Thereof, nor any of their employees, makes any warranty, express or implied, or assumes any legal liability or responsibility for the accuracy, completeness, or usefulness of any information, apparatus, product, or process disclosed, or represents that its use would not infringe privately owned rights. Reference herein to any specific commercial product, process, or service by trade name, trademark, manufacturer, or otherwise does not necessarily constitute or imply its endorsement, recommendation, or favoring by the United States Government or any agency thereof. The views and opinions of authors expressed herein do not necessarily state or reflect those of the United States Government or any agency thereof. 


\section{DISCLAIMER}

Portions of this document may be illegible in electronic image products. Images are produced from the best available original document. 


\section{PAGES 1 to 347 WERE INTENTIONALLY LEFT BLANK}


ranges over all possible combinations of weapons and troop dispositions, subject to certain restrictions, e.g., budget, number of troops, terrain, military objective, etc. This game is, of course, far beyond present computational capabilities, and a very much simplified version is treated here.

Some restriction must be put on the formations that can be employed. For example, a good defense against an atomic weapon is to disperse troops by placing men so that any given man is 100 miles away from the nearest man of the remaining troops. This is clearly militarily ineffective, however, and Lanchester theory is used to judge the effectiveness of a military formation. The body of this paper treats the way in which the theory is employed to handle formations.

\section{METHOD}

Assume that each man in a force has a certain fire power independent of the size of the group. Further, a "basic" group exists for both the attacker and defender in the sense that it is the most desirable operational size of a group. The number of groups in a certain for mation of troops is thus measured in terms of multiples of this fundamental group and is a function of the total number of men available and the number of men required for a fundamental group. Consequently, after a weapon system has been employed, one can then assess the damage to each of these basic groups. Suppose that the attacking force has $\mathrm{n}$ basic groups and, after a weapon system has been employed by the defending force, each attacking group $A_{i}$ contains $n_{i}$ men, each with firepower K. 1 Further, suppose the defending force has $\mathrm{m}$ basic groups and, after a weapon system has been employed by the attacking force, each defensive group $D_{i}$ consists of $m_{i}$ men, each with fire power $L$. The remaining groups $A_{i}$ and $D_{i}$ are then allowed to make engagements (the method of engagement will depend upon the location of the groups) one at a time, and the expected number of men destroyed, as a function of the time of the engagement, satisfies the Lanchester decay law; i.e., if a group $A_{i}$ engages group $D_{i}$, and the expected numbers of men at any time, $t$, of the attacking and defending forces are $\mathrm{y}$ and $\mathrm{x}$, respectively, then

$$
\frac{d y}{d t}=-L x
$$

and

$$
\frac{d x}{d t}=-K y
$$

with the initial conditions

and

$$
y(0)=m_{i}
$$

$$
x(0)=n_{i}
$$

By taking into account the time at which groups can engage, regroup, etc., and by a repeated application of this law, one can determine who wins; or, more precisely, one can determine

\footnotetext{
IOne could allow the firepower per man to change with the number of men in the group, but we assume in this paper that this firepower is constant.
} 
the expected number of men remaining on each side as a function of time. If one defines "annihilation time" as that time at which one of the forces looses all its men, one could consider the payoff from such an encounter as the difference between the number of men remaining for the attacking force and the number remaining for the defending force at the annihilation time.

If the expected number of men remaining is not a desirable payoff function, one could use the more general Lanchester equations for the probability that a certain number of men remain for the attacking and defending forces at time $t$. For a discussion of these more general equations, see J. R. Isbell and W. H. Marlow, "Attrition Games," Naval Research Logistics Quarterly, Vol. 3, 1956, pp 71-93. In this paper, to illustrate the ideas, only Equations (1) will be considered.

The calculations involved in the general procedure outlined above would be extremely complicated and, therefore, it is assumed in the remainder of this paper that the number of men remaining immediately after the engagement of two groups is determined by the solution of Lanchester's Equations (1) at the annihilation time. Also, it is assumed that the errors in the delivery of the weapons are zero, and the ratio, $\mathrm{K} / \mathrm{L}$, of the firepowers is one.

The remainder of the paper is devoted to a discussion of three examples which illustrate how this method may be applied. Although the division into basic groups is artificial, it is felt that the results are still informative.

\section{EXAMPLES}

\section{Atomic Weapons for Defensive Forces Only}

Consider the close-support situation in which only the defensive forces have access to atomic weapons. The defensive forces are supposed to consist of $M$ men, each with firepower $K$, and these men are in a rectangle $600 \mathrm{x}$ 3600 yards. In this problem, the configuration of the defensive forces is not important. They are assumed to be in a rectangle so that this same model can be used in the later problems. The attacker, with a total of $\mathrm{N}$ men, each with firepower $\mathrm{L}$, is assumed to assemble his men into basic rectangular groups of dimension $600 \times 3600$ yards, but he is allowed to have many such groups. Fur thermore, the attacker always assembles his

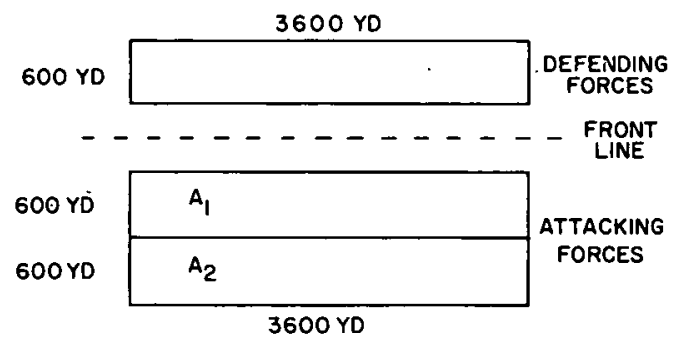

Figure 1-Battle situation when the attacker has two groups, $A_{1}$ and $A_{2}$ basic groups in the manner shown in Figure

1. The firepower per man, L, of each man in the attacking force is assumed to be independent of the dispersion of the total number of troops, N. Furthermore. $\mathrm{L} / \mathrm{K}=1$.

A strategy for the defender is the choice of a weapon system, whereas the strategy for the attacker is the choice of the number, W, of basic groups in which to divide his men. For simplicity in the calculations, the defender must choose among the four weapon systems of Table 1, and the attacker can divide his forces into only one, two, three, or four groups. Furthermore, each weapon system has a fixed set of aim points, chosen on a line parallel to the front line (Figure 1) and chosen so that the friendly troops will be safe. Assuming zero delivery errors, one can then easily calculate the effectiveness of a given weapon system against any of the formations the attacker may choose to employ; i.e., if the formation consists of $\mathrm{k}$ basic groups, one can calculate the number of men, $\mathrm{N}_{\mathrm{ij}}$, remaining in the group $\mathrm{A}_{\mathrm{i}}$, 
$\mathrm{i}=1,2, \ldots, \mathrm{k}$ of the attacker after the defender has employed a weapon system $\mathrm{j}$, $\mathrm{j}=1,2, \ldots, 4$. The numbers $\mathrm{N}_{\mathrm{ij}}$ are given in Table 2 .

TABLE 1

-Weapon Systems Available to the Defender

\begin{tabular}{|c|c|c|c|}
\hline Weapon system & 1 & 2 & 3 \\
\hline Number of weapons . & 1 & - 2 & 3 \\
\hline Effect radius of each weapon (yds) & 1100 . & 950 & 850 \\
\hline
\end{tabular}

TABLE 2

Number of Men Remaining in Each Group $A_{i}$ of Attacker's Force Áfter Employment of Weapon System by Defender When Attacker Has $k$ Basic Groups and Total of $\mathrm{N}$ Men

\begin{tabular}{|c|c|c|c|c|c|}
\hline \multirow{2}{*}{$\begin{array}{c}\text { No. of } \\
\text { Group, k }\end{array}$} & \multirow{2}{*}{ Group } & \multicolumn{5}{|c|}{ Weapon System } \\
\cline { 3 - 6 } & & 1 & 2 & 3 & 4 \\
\hline \hline 1 & $\mathrm{~A}_{1}$ & $0.67 \mathrm{~N}$ & $0.3 \mathrm{~N}$ & $0.348 \mathrm{~N}$ & $0.061 \mathrm{~N}$ \\
\hline \multirow{2}{*}{2} & $\mathrm{~A}_{1}$ & $0.33 \mathrm{~N}$ & $0.153 \mathrm{~N}$ & $0.174 \mathrm{~N}$ & $0.031 \mathrm{~N}$ \\
& $\mathrm{~A}_{2}$ & $0.19 \mathrm{~N}$ & 0 & 0 & $0.197 \mathrm{~N}$ \\
\hline 3 & $\mathrm{~A}_{1}$ & $0.22 \mathrm{~N}$ & $0.091 \mathrm{~N}$ & $0.116 \mathrm{~N}$ & $0.021 \mathrm{~N}$ \\
& $\mathrm{~A}_{2}$ & $0.126 \mathrm{~N}$ & 0 & 0 & $0.129 \mathrm{~N}$ \\
& $\mathrm{~A}_{3}$ & $0.126 \mathrm{~N}$ & $0.031 \mathrm{~N}$ & $0.087 \mathrm{~N}$ & $0.33 \mathrm{~N}$ \\
\hline & $\mathrm{A}_{1}$ & $0.167 \mathrm{~N}$ & $0.076 \mathrm{~N}$ & $0.087 \mathrm{~N}$ & $0.015 \mathrm{~N}$ \\
& $\mathrm{~A}_{2}$ & $0.095 \mathrm{~N}$ & 0 & 0 \\
$0.095 \mathrm{~N}$ & $0.035 \mathrm{~N}$ & $0.087 \mathrm{~N}$ & $0.25 \mathrm{~N}$ \\
& $\mathrm{~A}_{3}$ & $0.095 \mathrm{~N}$ \\
& $\mathrm{~A}_{4}$ & $0.167 \mathrm{~N}$ & $0.227 \mathrm{~N}$ & $0.25 \mathrm{~N}$ & $0.25 \mathrm{~N}$ \\
\hline
\end{tabular}

The Lanchester theory is applied in the following manner. Suppose the attacker has chosen two basic groups and the defender has chosen weapon system 1. After the defender employs the weapon system, the attacker has $0.33 \mathrm{~N}$ and $0.19 \mathrm{~N}$ men remaining in Groups $\mathrm{A}_{1}$ and $A_{2}$, respectively. It is then assumed that Group $A_{1}$ is the first to attack the defender, then $A_{2}$, and each new attack is made against the remaining men of the defender. For any such attack, the Lanchester theory always leads to complete annihilation of one group and the number of men remaining after all attacks have been made are recorded in the appropriate place in Table 3. The negative numbers in the table correspond to annihilation of the attacking force; the function ${ }^{2} g(x)=(\operatorname{sgn} x) \sqrt{|x|}$, and $\dot{H}=(M / N)^{2}$. (The numbers in the table have been normalized on $\mathrm{N}$, but this does not affect the strategies in the game.)

2 The term $\operatorname{sgn} x$ is equal to the algebraic sign of $x$ : 
TABLE 3

General Payoff Matrix for the Game in Which Only the Defender Has Atomic Weapons, $g(x)=(\operatorname{sgn} x) \sqrt{|x|}, H=(M / N)^{2}$

\begin{tabular}{|c|c|c|c|c|}
\hline \multirow{2}{*}{$\begin{array}{c}\text { No. of } \\
\text { Groups, k }\end{array}$} & \multicolumn{5}{|c|}{ Weapon System } \\
\cline { 2 - 5 } & 1 & 2 & 3 & 4 \\
\hline \hline 1 & $\mathrm{~g}(0.445-\mathrm{H})$ & $\mathrm{g}(0.090-\mathrm{H})$ & $\mathrm{g}(0.121-\mathrm{H})$ & $\mathrm{g}(0.004-\mathrm{H})$ \\
2 & $\mathrm{~g}(0.145-\mathrm{H})$ & $\mathrm{g}(0.023-\mathrm{H})$ & $\mathrm{g}(0.030-\mathrm{H})$ & $\mathrm{g}(0.040-\mathrm{H})$ \\
3 & $\mathrm{~g}(0.070-\mathrm{H})$ & $\mathrm{g}(0.009-\mathrm{H})$ & $\mathrm{g}(0.021-\mathrm{H})$ & $\mathrm{g}(0.127-\mathrm{H})$ \\
4 & $\mathrm{~g}(0.074-\mathrm{H})$ & $\mathrm{g}(0.058-\mathrm{H})$ & $\mathrm{g}(0.078-\mathrm{H})$ & $\mathrm{g}(0.135-\mathrm{H})$ \\
\hline
\end{tabular}

Observe that if $x_{2}>x_{1}$, then $g\left(x_{2}\right)>g\left(x_{1}\right)$. For if $x_{2}>x_{1}>0$, then $g\left(x_{2}\right)-g\left(x_{1}\right)=$ $\sqrt{x_{2}}-\sqrt{x_{1}}>0$; if $x_{2}>0>x_{1}$, then $g\left(x_{2}\right)-g\left(x_{1}\right)=\sqrt{x_{2}}-\sqrt{\left|x_{1}\right|}>0$; and if $0>x_{2}>x_{1}$, then $\left|x_{1}\right|>\left|x_{2}\right|$ and $g\left(x_{2}\right)-g\left(x_{1}\right)=-\sqrt{\left|x_{2}\right|}+\sqrt{\left|x_{1}\right|}>0$. From this fact, it is easily seen that for every value of $H$ the element in the second column and the $j^{\text {th }}$ row of the matrix of Table 3 is less than each of the elements in the first and third columns of the $j^{\text {th }}$ row for $j=1,2,3$, and 4. Therefore, the defender will never use weapon system 1 or 3 , and the above game is equivalent to the game with payoff matrix given in Table 4.

Using the same reasoning as above, one sees that the element in the fourth row and the $\mathrm{j}^{\text {th }}$ column of the matrix in Table 4 is greater for every value of $\mathrm{H}$ than each of the elements in the second and third rows of the $j^{\text {th }}$ column for $j=1$ and 2 . Therefore, the attacker will never divide his troops into either two or three groups, and the game is finally reduced to the game with payoff matrix given in Table 5 .

TABLE 4

General Payoff Matrix for the Game Equivalent to the Game in Which Only the Defender has Atomic Weapons, $g(x)=(\operatorname{sgn} x) \sqrt{|x|}, H=(M / N)^{2}$

\begin{tabular}{|c|c|c|}
\hline \multirow{2}{*}{$\begin{array}{c}\text { No. of } \\
\text { Groups, k }\end{array}$} & \multicolumn{2}{|c|}{ Weapon System } \\
\cline { 2 - 3 } & 2 & 4 \\
\hline \hline 1 & $\mathrm{~g}(0.090-\mathrm{H})$ & $\mathrm{g}(0.004-\mathrm{H})$ \\
2 & $\mathrm{~g}(0.023-\mathrm{H})$ & $\mathrm{g}(0.040-\mathrm{H})$ \\
3 & $\mathrm{~g}(0.009-\mathrm{H})$ & $\mathrm{g}(0.127-\mathrm{H})$ \\
4 & $\mathrm{~g}(0.058-\mathrm{H})$ & $\mathrm{g}(0.135-\mathrm{H})$ \\
\hline
\end{tabular}

TABLE 5

General Payoff Matrix for the Game Equivalent to the Game in Which Only the Defender has Atomic Weapons, $\mathrm{g}(\mathrm{x})=(\operatorname{sgn} \mathrm{x}) \sqrt{|\mathrm{X}|}, \mathrm{H}=(\mathrm{M} / \mathrm{N})^{2}$

\begin{tabular}{|c|c|c|}
\hline \multirow{2}{*}{$\begin{array}{c}\text { No. of } \\
\text { Groups, }\end{array}$} & \multicolumn{2}{|c|}{ Weapon System } \\
\cline { 2 - 3 } & 2 & 4 \\
\hline \hline 1 & $\mathrm{~g}(0.090-\mathrm{H})$ & $\mathrm{g}(0.004-\mathrm{H})$ \\
4 & $\mathrm{~g}(0.058-\mathrm{H})$ & $\mathrm{g}(0.135-\mathrm{H})$ \\
\hline
\end{tabular}

For any value of $\mathrm{H}$, an optimal strategy for the attacker consists of specifying the probabilities of dividing his troops into four groups and of not dividing his troops, whereas an optimal strategy for the defender is the probabilities of using weapon systems 2 and 4. 


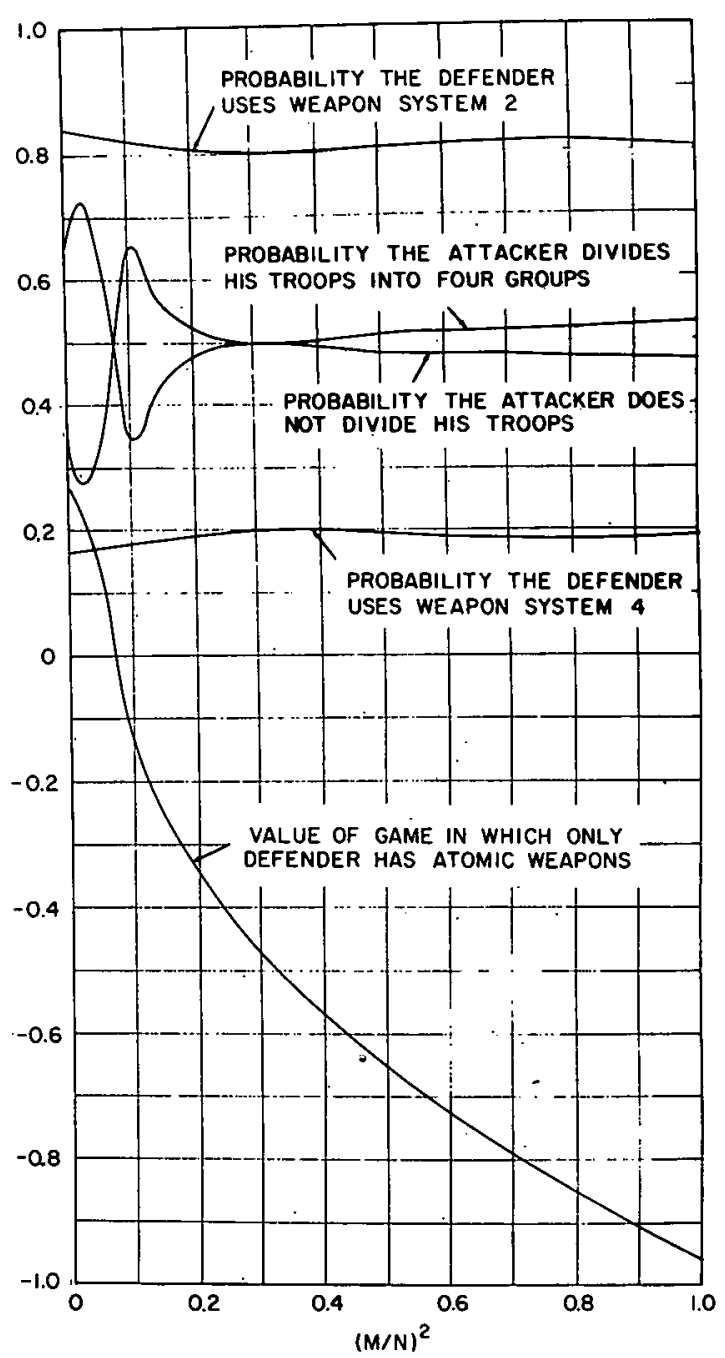

Figure 2 - Solution of the game in which only the defender has atomic weapons, as a function of $(\mathrm{M} / \mathrm{N})^{2}$
Figure 2 shows these optimal strategies, together with the value of the game as a function of $(\mathrm{M} / \mathrm{N})^{2}$. Note that the solution of the general $4 \times 4$ game in Table 3 does not involve strategies 2 and 3 for the attacker and strategies 1 and 3 for the defender.

A few points on this curve are of particular interest. For example, the point at which the value of the game is zero may be taken as a measure of the value of an atomic weapons system in terms of men. More specifically, if the defender has access to atomic weapons and the attacker does not, then the defender needs only approximately 0.28 as many men as the attacker to have the same capability.

Also, if the attacker and defender initially have the same number of men, say 1000 , then the expected number of men remaining for the defender is 950 and for the attacker is zero.

\section{Atomic Weapons for Both Offensive and} Defensive Forces

In this section, the battle situation will be the same as discussed in Example 1, except that the defending forces will now be allowed to divide into groups. Further, it is assumed that the defensive forces will be better protected against atomic weapons and, therefore, the radii of effect of the

attacker's weapons are taken to be smaller than those for the defender. The available weapon systems for the attacker and defender are given in Table 6. Both the attacker and defender are allow ed to present their forces in either one or four basic groups. (A basic group is a rectangle $600 \times 3600$ yards.)

If one applies the method described in Example 1 and lets ( $i, j$ ) denote a strategy which consists of a choice of weapon system $j$ and a formation composed of $i$ groups, then one can calculate the payoff matrix of Table 7.

From the reasoning in Example 1, it is easily seen that for. every value of $\mathrm{H}$ the defender always prefers strategy $(1,1)$ to $(4,1)$, and strategy $(1,2)$ to $(4,2)$. Therefore, this $4 \times 4$ rectangular game is equivalent to a $4 \times 2$ game, with the strategies for the defender being $(1,1)$ and $(1,2)$. Furthermore, in this reduced game, the attacker always prefers $(1,2)$ to $(1,1)$, and $(4,2)$ to $(4,1)$. Consequently, the game is reduced to an equivalent game with payoff matrix given by Table 8 . 
TABLF, 6

Weapon Systems Available to Attacker and Defender

\begin{tabular}{|l|c|c|c|c|}
\hline & \multicolumn{2}{|c|}{$\begin{array}{c}\text { Attacker's weapon } \\
\text { systems }\end{array}$} & \multicolumn{2}{|c|}{$\begin{array}{c}\text { Defender's weapon } \\
\text { systems }\end{array}$} \\
\cline { 2 - 5 } & 1 & 2 & 1 & 2 \\
\hline \hline $\begin{array}{l}\text { Number of weapons } \\
\text { Effect radius of } \\
\text { each weapon (yds) }\end{array}$ & 2 & 4 & 2 & 4 \\
\hline
\end{tabular}

TABLE 7

General Payoff Matrix for the Game in Which Both Defender and

Attacker Have Atomic Weapons, $g(x)=(\operatorname{sgn} x) \sqrt{|x|}, H=(M / N)^{2}$

\begin{tabular}{|c|c|c|c|c|}
\hline \multirow{2}{*}{$\begin{array}{c}\text { Strategies } \\
\text { for the } \\
\text { Attacker }\end{array}$} & $(1,1)$ & $(1,2)$ & $(4,1)$ & $(4,2)$ \\
\cline { 2 - 5 } & & & & \multicolumn{4}{|c|}{ Strategies for the Defender } \\
\hline \hline$(1,1)$ & $\mathrm{g}(0.090-0.620 \mathrm{H})$ & $\mathrm{g}(0.004-0.620 \mathrm{H})$ & $\mathrm{g}(0.090-0.101 \mathrm{H})$ & $\mathrm{g}(0.004-0.101 \mathrm{H})$ \\
$(1,2)$ & $\mathrm{g}(0.090-0.204 \mathrm{H})$ & $\mathrm{g}(0.004-0.204 \mathrm{H})$ & $\mathrm{g}(0.090-0.163 \mathrm{H})$ & $\mathrm{g}(0.004-0.163 \mathrm{H})$ \\
$(4,1)$ & $\mathrm{g}(0.056-0.620 \mathrm{H})$ & $\mathrm{g}(0.135-0.620 \mathrm{H})$ & $\mathrm{g}(0.056-0.101 \mathrm{H})$ & $\mathrm{g}(0.135-0.101 \mathrm{H})$ \\
$(4,2)$ & $\mathrm{g}(0.056-0.204 \mathrm{H})$ & $\mathrm{g}(0.135-0.204 \mathrm{H})$ & $\mathrm{g}(0.056-0.163 \mathrm{H})$ & $\mathrm{g}(0.135-0.163 \mathrm{H})$ \\
\hline
\end{tabular}

TABLE 8

General Payoff Matrix for the Game Equivalent to the Game in Which Both Defender and Attacker Have Atomic Weapons, $g(x)=(\operatorname{sgn} x) \sqrt{|x|}$, $\mathrm{H}=(\mathrm{M} / \mathrm{N})^{2}$

\begin{tabular}{|c|c|c|}
\hline \multirow{2}{*}{$\begin{array}{c}\text { Strategies } \\
\text { for the } \\
\text { Attacker }\end{array}$} & \multicolumn{2}{|c|}{ Strategies for the Defender } \\
\cline { 2 - 3 } & $(1,1)$ & $(1,2)$ \\
\hline \hline $\begin{array}{c}(1,2) \\
(4,2)\end{array}$ & $\mathrm{g}(0.090-0.204 \mathrm{H})$ & $\mathrm{g}(0.004-0.204 \mathrm{H})$ \\
$\mathrm{g}(0.056-0.204 \mathrm{H})$ & $\mathrm{g}(0.135-0.204 \mathrm{H})$ \\
\hline
\end{tabular}

Table 8 shows that for any value of $\mathrm{H}^{\prime}$ an optimal strategy for the attacker consists of the employment of weapon system 2 and the specification of the probabilities of dividing his ' troops into one and four groups, whereas the defender never divides his troops and must specify the probabilities of employing weapon systems 1 and 2. Figure 3 shows these optimal strategies together with the value of the game as a function of $(\mathrm{M} / \mathrm{N})^{2}$. Note that the solution of the general $4 \times 4$ game in Table 7 does not involve strategies $(1,1)$ and $(4,1)$ for the attacker and strategies $(4,1)$ and $(4,2)$ for the defender. 


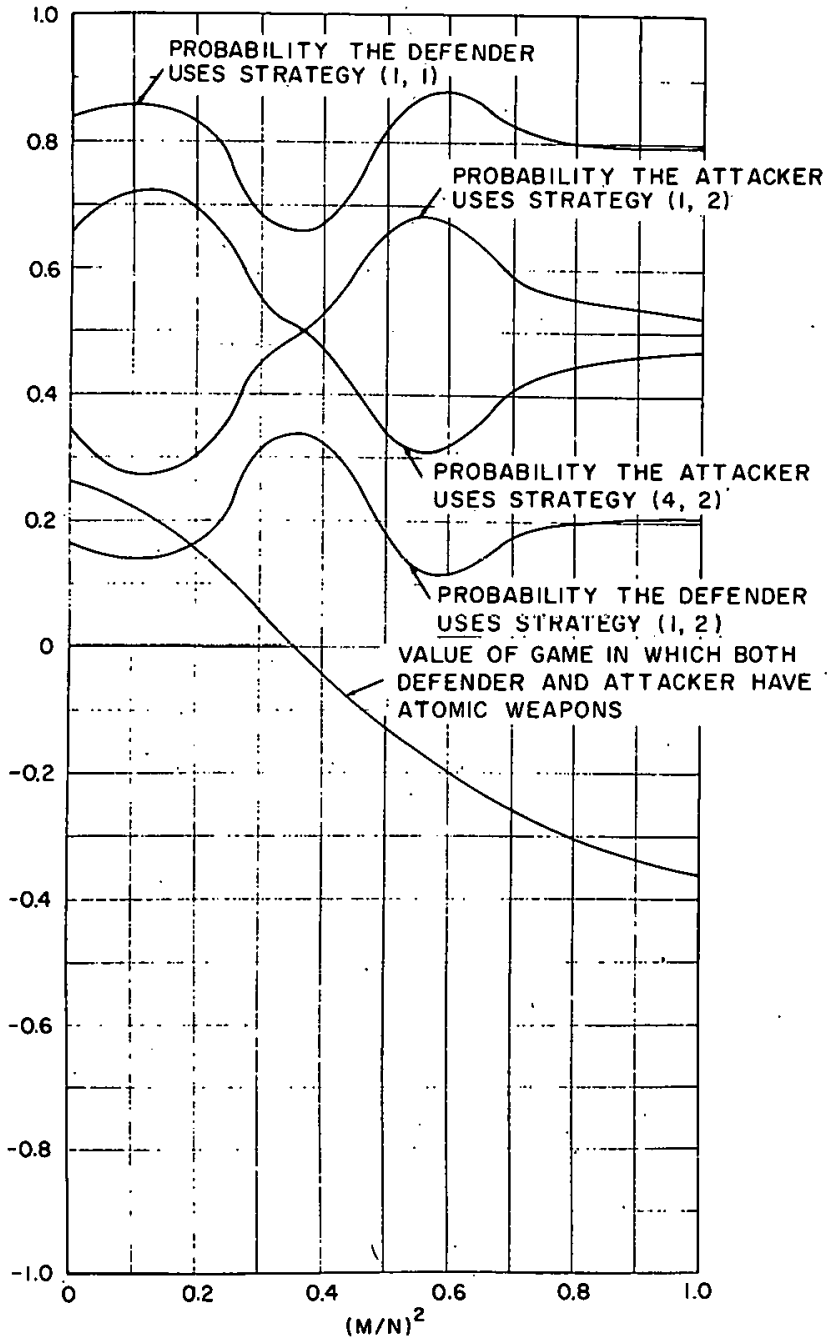

Figure 3 - Solution of the game in which both the defender and the attacker have atomic weapons, as a function of $(\mathrm{M} / \mathrm{N})^{2}$

The point on Figure 3 at which the value of the game is zero may be taken as a measure of the value of being prepared for an atomic burst in terms of men. More specifically, if both the defending and attacking forces have access to atomic weapons and the defending forces are unwarned, then the defending forces need approximately 0.60 as many man as the attacker to have the same capability.

Also, if the attacker and defender initially have the same number of men, say 1000 , the expected number of men remaining for the defender is 360 and for the attacker is zero.

3. Optimal Aiming Procedure When Only the Defender Has an Atomic Weapon System

In Example 3, the battle situation is the same as that discussed in Example 1, except the defender will have only one weapon system consisting of four weapons each with an effect radius of 550 yards. The defender will have a choice of five aiming procedures, as shown in Figure 4.

Figure 4 - Aiming procedures

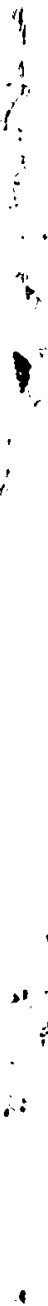
for the defender. Rectangles represent "basic" groups of attacker's forces. Circles effects of weapons used by defender. Each numindicates a different situation. Defender's forces (not shown) are below attacker's forces. 
By applying the methods described in Example 1, one can show that the payoff matrix is given by Table 9 .

TABLE 9

General Payoff Matrix for the Game in Which the Defender Has an Atomic Weapon System and Various Aiming Procedures, $g(x)=(\operatorname{sgn} x) \sqrt{|x|}, H=(M / N)^{2}$

\begin{tabular}{|c|c|c|c|c|c|}
\hline \multirow{2}{*}{$\begin{array}{c}\text { No. of } \\
\text { Groups, k }\end{array}$} & \multicolumn{5}{|c|}{ Aiming Procedure } \\
\cline { 2 - 6 } & 1 & 2 & 3 & 4 & 5 \\
\hline \hline 1 & $\mathrm{~g}(0.445-\mathrm{H})$ & $\mathrm{g}(0.226-\mathrm{H})$ & $\mathrm{g}(0.090-\mathrm{H})$ & $\mathrm{g}(0.075-\mathrm{H})$ & $\mathrm{g}(0.265-\mathrm{H})$ \\
2 & $\mathrm{~g}(0.145-\mathrm{H})$ & $\mathrm{g}(0.078-\mathrm{H})$ & $\mathrm{g}(0.036-\mathrm{H})$ & $\mathrm{g}(0.060-\mathrm{H})$ & $\mathrm{g}(0.158-\mathrm{H})$ \\
3 & $\mathrm{~g}(0.070-\mathrm{H})$ & $\mathrm{g}(0.065-\mathrm{H})$ & $\mathrm{g}(0.080-\mathrm{H})$ & $\mathrm{g}(0.096-\mathrm{H})$ & $\mathrm{g}(0.100-\mathrm{H})$ \\
4 & $\mathrm{~g}(0.074-\mathrm{H})$ & $\mathrm{g}(0.098-\mathrm{H})$ & $\mathrm{g}(0.108-\mathrm{H})$ & $\mathrm{g}(0.093-\mathrm{H})$ & $\mathrm{g}(0.079-\mathrm{H})$ \\
\hline
\end{tabular}

It is clear that the attacker always prefers having his troops in one group to having his troops in two groups. Consequently, the game is equivalent to the $3 \times 5$ game obtained from Table 9 with the second row deleted.

This game is solved for only one value of $\mathrm{H}$, namely, $\mathrm{H}=0.08$. The value of the game is 0.075 , and the attacker uses strategies 1,3 , and 4 with probabilities $0.24,0.45$, and 0.31 , respectively, where the defender uses strategies 1,3 , and 4 with probabilities $0.21,0.03$, and 0.76 , respectively.

It is interesting to note the variation of the value of this game to certain reduced games for $\mathrm{H}=0.08$. For example, if the defender is allowed only strategies 1 and 4 , then the value of the game is 0.077 . If he is allowed only strategies 1,2 , and 4 ; then the value of the game is 0.076 .

Notice also that the optimal aiming procedure does not involve only the aiming procedures which are optimal against each of the fixed dispersion patterns for the attacker. In this case, suboptimization is not valid.

\section{CONCLUSIONS}

A method was introduced for combining the techniques of classical Lanchester theory of combat with those of game theory toward the end of selecting optimal strategies in combat with special weapons. In the application of this method to the example in which only the defender had atomic weapons, it was shown that the attacker always chose either to disperse his troops the maximum amount or not to disperse his troops at all. The defender always chose to employ a mixed strategy consisting of the weapon systems of either two intermediate weapons or four small weapons.

If both the defender and attacker had access to atomic weapons, then the optimal strategy for the attacker was to employ the weapon system consisting of four small weapons and to use a mixed strategy for the dispersion of his troops. On the other hand, the defender never dispersed his troops and always used a mixed strategy for the weapon systems. 
In the example where the defender has a fixed weapon system and chooses to optimize his aiming procedure, it was shown that the optimal aiming procedure does not involve only the aiming procedures which are optimal against each of the fixed dispersion patterns for the attacker.

The model discussed in this paper is far from realistic, but the authors feel that certain interesting trends may be obtained by such elementary discussions. Two ways in which to approach more realism are to introduce into the combat the time at which the different groups become engaged, as discussed at the beginning of the section on "Method," and to obtain a more realistic model for the basic group discussed within the same section. 